there is an enormous variation in rate.

We have attempted to model the variations. The model is based on the previous work of Woodward and Hoffmann, ${ }^{5}$ who showed that one can identify especially active reaction pathways in reactions of organic and simple inorganic molecules by examining the symmetry of the orbitals available for reaction. In general, it has been found that a reaction is fast, if the orbitals of the right symmetry are present, while it is slow if they are absent.

Banholzer et al. ${ }^{3}$ examined the reaction $\mathbf{N O}_{(\mathrm{ad})} \rightarrow \mathrm{N}_{(\mathrm{ad})}$ $+\mathrm{O}_{(\mathrm{ad})}$ in detail and noted that the availability of the antibonding orbitals needed to break the $\pi$ bond in the NO varies significantly from face to face. Figure 1 also shows the site average orbital availability calculated as a function of crystal face. One observes that on $\mathrm{Pt}(111)$ there are no orbitals of the right symmetry available for reaction while on $\mathrm{Pt}(410)$ all the necessary orbitals are present. There is a continuous variation in the orbital availability for faces in between.

A comparison of the data and the calculations shows that the orbital availability is a good indicator of the catalytic activity. The rate is low when the orbital availability is low and high when the orbital availability is high. The magnitude of the effect is enormous. The changes in orbital avail- ability explain why $\mathrm{Pt}(210)$ is less active than $\mathrm{Pt}(410)$ and why $\mathrm{Pt}(511)$ is less active than $\mathrm{Pt}(100)$. Neither of these observations is easily explained by previous models. Clearly, the orbital availability is not the only effect; $\mathrm{Pt}(210)$, for instance, is slightly more active than $\mathrm{Pt}(100)$ even though the orbital availabilities of the two faces are the same. However, the effects of changes in the orbital availability explains much of the data. These effects need to be more extensively explored.

Acknowledgments: This work was supported by the National Science Foundation under Grant No. CPE83-11791. This work made use of the University of Illinois Center for Microanalysis of Materials which is supported under Grant No. DMR83-16981.

${ }^{1}$ R. J. Gorte, L. D. Schmidt, and J. L. Gland, Surf. Sci. 109, 367 (1981).

${ }^{2}$ H. P. Bonzel, G. Broden, and G. Pirug, J. Catal. 53, 96 (1978).

${ }^{3}$ W. F. Banholzer, Y. O. Park, K. M. Mak, and R. I. Masel, Surf. Sci. 128 $176(1983)$.

${ }^{4}$ Y. O. Park, W. F. Banholzer, and R. I. Masel, Appl. Surf. Sci. 19, 145 (1984), and references therein.

${ }^{5}$ R. B. Woodward and R. Hoffmann, The Conservation of Orbital Symmetry (Chemie, Weinheim, 1969).

\title{
Summary Abstract: Comparative studies of alkane activation by low-index surfaces of iridium and platinum ${ }^{\text {a) }}$
}

\author{
P. D. Szuromi, J. R. Engstrom, T. S. Wittrig, b) and W. H. Weinberg \\ Division of Chemistry and Chemical Engineering, California Institute of Technology, Pasadena, California \\ 91125
}

(Received 29 October 1984; accepted 4 December 1984)

The interaction of alkanes with low-index surfaces of iridium at low temperatures and pressures has been studied in our laboratory by thermal desorption mass spectrometry and low-energy electron diffraction. ${ }^{1,2}$ While the reconstructed $(110)-(1 \times 2)$ surface of iridium initiates dissociative chemisorption of ethane and all higher alkanes at $125 \mathrm{~K}$ in the low coverage limit, similar reactions with the closepacked (111) surface occur readily only at defect sites. ${ }^{1}$ Thus, surface geometry influences strongly the activation barriers to $\mathrm{C}-\mathrm{H}$ bond scission in alkanes on iridium surfaces.

Likewise on the $\mathrm{Pt}(111)$ surface, normal alkanes which desorb molecularly below $250 \mathrm{~K}$ do not adsorb dissociatively under similar conditions. ${ }^{3}$ On the other hand, both $n$-butane and $n$-pentane are observed to adsorb dissociatively on the $\mathrm{Pt}(110)-(1 \times 2)$ surface. This demonstrates that the surface structure sensitivity of alkane activation, which was observed on iridium surfaces, occurs also on platinum surfaces.

Low exposures $(<0.5 \mathrm{~L})$ of $n$-butane and $n$-pentane adsorb dissociatively on $\operatorname{Pt}(110)-(1 \times 2)$ with a threshold temperature of approximately $200 \mathrm{~K}$. The hydrocarbon fragments which form evolve hydrogen which is manifest as thermal desorption features at approximately 300, 400, and $550 \mathrm{~K}$. At higher exposures, molecular desorption of the parent alkanes is observed at $200 \mathrm{~K}$ for $n$-butane and $230 \mathrm{~K}$ for $n$-pentane. No hydrocarbons other than the parent alkane which was adsorbed are observed in the thermal desorption spectra. The hydrogen feature at $300 \mathrm{~K}$ appears to arise from the desorption of hydrogen bound to the platinum surface, while the features at approximately 400 and $550 \mathrm{~K}$ are a consequence of the decompositon of hydrocarbon fragments adsorbed on the surface. Saturation coverages of the dissociatively adsorbed alkanes, after adsorption at $150 \mathrm{~K}$, in units of $10^{13}$ molecules $\mathrm{cm}^{-2}$, are $4.0 \pm 0.4$ for $n$-butane and $5.0 \pm 0.5$ for $n$-pentane, based on the known coverage of hydrogen at saturation reported by Jackman et al., ${ }^{4}$ namely $1.1 \times 10^{15}$ atoms $\mathrm{cm}^{-2}$. During these thermal desorption measurements, no loss of intensity of the half-order LEED beams is observed, demonstrating that the reconstruction of $\operatorname{Pt}(110)$ is not relaxed by alkane adsorption.

The dissociative adsorption of $n$-butane can be inhibited by preadsorption of hydrogen. The extent of inhibition is linear in precoverage of hydrogen, and is complete after a preexposure of $0.5 \mathrm{~L}$ of hydrogen. Furthermore, if $0.5 \mathrm{~L}$ of hydrogen is exposed to the surface after the adsorption of $n$ butane at $150 \mathrm{~K}$, then the dissociative adsorption of the $n$ butane is inhibited completely. However, if the adlayer of $n$ - 
butane is annealed to $200 \mathrm{~K}$, then exposure of hydrogen has no inhibiting effect on dissociative adsorption. This threshold temperature for dissociative adsorption of $200 \mathrm{~K}$ implies an activation energy of approximately $12 \mathrm{kcal} / \mathrm{mol}$. This is consistent with the observed absence of dissociative adsorption for propane, for which only molecular desorption is observed at $170 \mathrm{~K}$.

The $\operatorname{Pt}(110)-(1 \times 2)$ surface activates alkanes at low temperatures $(\sim 200 \mathrm{~K})$ and pressures, although this activation is not so effective as that observed on the same surface of iridium. On iridium the threshold temperature for dissociative adsorption is only $125 \mathrm{~K}$, and somewhat higher saturation coverages of dissociatively adsorbed overlayers are observed. While differences in the details of the reaction chemistry are manifestations of electronic structural differ- ences between the metals, for both metals the availability of high coordination adsites appears to lower the kinetic barriers that must be overcome to activate carbon-hydrogen bonds in alkanes.

\footnotetext{
a) Supported by the National Science Foundation under Grant. No. CHE8206487.

b) Current address: Amoco Oil Co., P. O. Box 400, Naperville, Illinois 60566.

${ }^{1}$ W. H. Weinberg, Surv. Prog. Chem. 10, 1 (1983).

${ }^{2}$ P. D. Szuromi and W. H. Weinberg, Surf. Sci. 149, 226 (1985).

${ }^{3}$ L. E. Firment and G. A. Somorjai, J. Chem. Phys. 66, 2901 (1977); L. E. Firment, Ph. D. thesis, University of California, Berkeley, 1976.

${ }^{4}$ T. E. Jackman, J. A. Davies, D. P. Jackson, W. N. Unertl, and P. R. Norton, Surf. Sci. 120, 389 (1982).
}

\title{
Summary Abstract: A molecular beam study of the dissociative adsorption of $\mathrm{CO}_{2}$ on $\mathrm{Ni}(100)$
}

\author{
G. E. Gdowski, A. V. Hamza, M. P. D'Evelyn, and R. J. Madix \\ Department of Chemical Engineering, Stanford University, Stanford, California 94305
}

(Received 17 October 1984; accepted 14 November 1984)

\begin{abstract}
A supersonic molecular beam system was used to study the dynamical characteristics of the dissociative adsorption of $\mathrm{CO}_{2}$ on $\mathrm{Ni}(100) . \mathrm{CO}_{2}$ dissociated into adsorbed $\mathrm{CO}$ and $\mathrm{O}$. The dissociative sticking probability $s_{0}$ was increased by two orders of magnitude by increasing the translational kinetic energy of the $\mathrm{CO}_{2}$ by a factor of slightly more than 12 . The addition of vibrational energy also increased $s_{0}$. Small amounts of oxygen completely poisoned the dissociation. The results also indicated that in addition to a direct activated route $\mathrm{CO}_{2}$ could dissociate through a molecularly adsorbed state.
\end{abstract}

A brief description of the reactive scattering apparatus will be given; for a more detailed description see Ref. 1 . The reactive scattering apparatus was equipped with low energy electron diffraction (LEED)/Auger electron spectroscopy

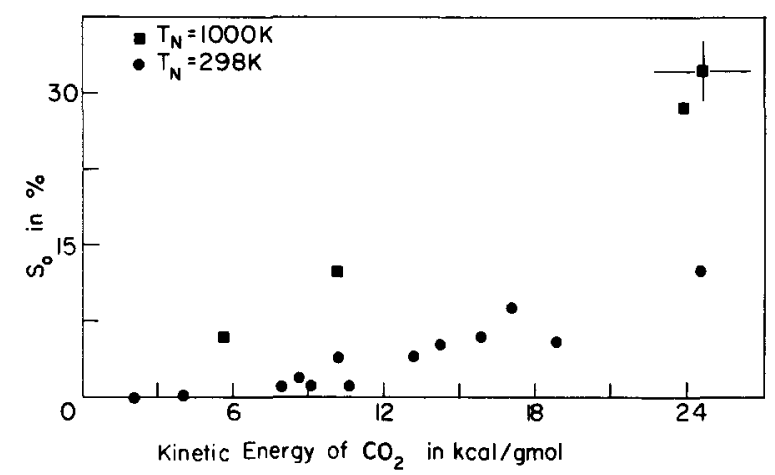

FIG. 1. The initial dissociative sticking probability for $\mathrm{CO}_{2}$ on $\mathrm{Ni}(100)$ as a function of the $\mathrm{CO}_{2}$ translational kinetic energy for nozzle temperatures of $298 \mathrm{~K}$ (circles) and $1000 \mathrm{~K}$ (squares).
(AES) optics, an ion gun for Ar sputtering, and two mass spectrometers. The mass spectrometers were used to determine beam energies and fluxes and for temperature programmed desorption (TPD) studies. The scattering chamber was pumped by a $1500 \mathrm{l} / \mathrm{s}$ turbomolecular pump, a $220 \mathrm{l} / \mathrm{s}$ vac-ion pump, and a titanium sublimation pump.

The supersonic molecular beam source could deliver up to $10^{15}$ molecules $/ \mathrm{cm}^{2} / \mathrm{s}$ to the sample. The duration of the beam dose was controlled by an electronically operated shutter, which intercepted the beam outside the scattering chamber. The kinetic energies of the $\mathrm{CO}_{2}$ beam ranged from 1.8 to $30 \mathrm{kcal} / \mathrm{mol}$. The beam energies were obtained by varying the temperature of the nozzle and by seeding $\mathrm{He}$ and $\mathrm{H}_{2}$ beams with $\mathrm{CO}_{2}$ (the lighter molecules accelerate the heavier $\mathrm{CO}_{2}$ molecules). ${ }^{2}$

Subsequent to exposure of the surface to $\mathrm{CO}_{2}$ at a surface temperature of $400 \mathrm{~K}, \mathrm{CO}$ was desorbed by TPD in the range of 450 to $470 \mathrm{~K}\left(\theta_{\mathrm{Co}}<0.03\right.$ monolayer) and oxygen remained on the surface as determined by AES. This allowed the use of $\mathrm{CO}$ TPD to measure the number of $\mathrm{CO}_{2}$ molecules dissociating. TPD data were calibrated with a saturation dose of $\mathrm{CO}$ at room temperature $\left(\theta_{\text {sat }}=0.55\right.$ monolayer $) .{ }^{3}$ To test this procedure the initial sticking probability of $\mathrm{CO}$ on $\mathrm{Ni}(100)$ was determined to be approximately 0.9 at two kinetic energies. The value is in good agreement with a previous determination of approximately unity. ${ }^{4}$

The data (Fig. 1) for the room temperature nozzle showed a 300-fold increase in $s_{0}$ with the $\mathrm{CO}_{2}$ beam energy. At low beam energies $s_{0}$ was $10^{-4}$, it then increased slowly to 0.02 at a beam energy of $\approx 9 \mathrm{kcal} / \mathrm{mol}$ and finally rose moderately to 0.13 at $25 \mathrm{kcal} / \mathrm{mol}$. In the energy range studies here $s_{0}$ did not appear to saturate with increasing incident energy. 